\title{
Migration/Refugee Law (2020)
}

\author{
Matthew Scott*
}

The momentum of legal and policy innovations recorded in recent years in the context of disaster displacement slowed somewhat in 2020 , no doubt in part as a consequence of the COVID-19 pandemic. Nonetheless, important developments at the international and regional levels reflect an increasing embeddedness of displacement in the context of disasters and climate change as an issue requiring concerted attention and action.

Whereas most attention to disaster- and climate change-related human mobility focuses on hazard events and other adverse impacts of climate change as drivers, the pandemic also called attention to how people in situations of displacement and migration may be differentially adversely affected by hazards that may also have a generalised impact on the wider population. ${ }^{1}$ Significantly, even though it did not have a direct impact on normative developments in 2020, the COVID-19 pandemic did prompt actors within the UN system to issue guidance based on existing international human rights law. The UN Committee on the Protection of the Rights of All Migrant Workers, together with the UN Special Rapporteur on the human rights of migrants, issued a 'Joint Guidance Note on the Impacts of the COVID-19 Pandemic on the Human Rights of Migrants, ${ }^{2}$ highlighting the importance of addressing the particular exposure and vulnerability of people in situations of displacement

* Senior researcher, head of People on the Move thematic area, Raoul Wallenberg Institute of Human Rights and Humanitarian Law.

** Contributions from UNHCR (Isabelle Michal, Madeline Garlick and Kees Wouters), гом (Pablo Escribano, Ileana-Sinziana Puscas, Bogdan Danila, and Alice Sironi) and the Platform on Disaster Displacement (Juan Carlos Méndez) are gratefully acknowledged. Any errors are my own.

1 See UNHCR and Potsdam Institute for Climate Impact Research (PIK), COVID-19, Displacement and Climate Change (2020) available at: $<$ https://reliefweb.int/sites/reliefweb.int/files/ resources/UNHCR\%20COVID-19\%2oDisplacement\%2oand\%2oClimate\%2oChange\%2oFact \%2oSheet\%2O-\%2OJune\%202020.pdf>, last accessed (as any subsequent URL) on 31 March 2021. See also the Iом research series on 'The COVID-19 Pandemic, Migration and the Environment' available from <https://environmentalmigration.iom.int/covid-19-pandemic -migration-and-environment $>$.

2 Available at <https://www.ohchr.org/Documents/Issues/Migration/CMWSPMJointGuidance NoteCOVID-19Migrants.pdf>. 
and migration, including people with irregular immigration status. A wide range of issues is addressed in the 'Joint Guidance Note', including concerns about access to social services and medical care, health and safety at work, freedom of movement and access to asylum, and other rights that are at risk of being denied in the context of pandemic containment measures. Although not considered in any depth in the 'Joint Guidance Note', the fact that disasters can give rise to situations of enforced "immobility" warrants further consideration by international lawyers. The notion of 'trapped populations' has long been recognised in the academic literature, ${ }^{3}$ but less attention has been paid to the international legal implications of this predicament. The CoviD-19 pandemic provides ample opportunity for this issue to receive further attention in the coming years.

\section{$2 \quad$ International Level}

A number of significant resolutions of the UN General Assembly, together with detailed guidance from UNHCR and the UN Special Rapporteur on the human rights of internally displaced persons further underscored the issue of internal and cross-border displacement in the context of disasters and climate change as one requiring the concerted attention of the international community. First, a series of General Assembly resolutions on sustainable development, disaster risk reduction, and climate change adaptation all called attention to the specific challenges presented by displacement. Second, UNHCR's 'Legal considerations regarding claims for international protection made in the context of the adverse effects of climate change and disasters', ${ }^{4}$ represents the most comprehensive legal engagement by the UN refugee agency on the subject since it first began addressing legal doctrinal issues relating to displacement in the context of disasters and climate change, such as at the Bellagio expert round table in 2011. ${ }^{5}$ Third, the 'Report of the UN Special Rapporteur on the human rights of internally displaced persons on displacement in the context of the slower onset adverse impacts of climate change, ${ }^{6}$ represents the first report by a UN mandate holder on this issue to the UN General Assembly, and follows the 2005 informal report by former Representative of the Secretary

3 Foresight, 'Migration and Global Environmental Change: Future Challenges and Opportunities' (UK Government Office for Science 2011).

4 Available at <https://www.refworld.org/docid/ 5 f 75 f 2734 .html $>$.

5 UNHCR, 'Summary of Deliberations on Climate Change and Displacement' (2011) available at <https://www.unhcr.org/4da2b5e19.pdf>.

6 A/75/207, available at $<$ https://undocs.org/A/75/207>. 
General on the human rights of IDPs Walter Kälin, writing in the aftermath of the 2004 Indian Ocean tsunami. These documents are considered in turn below.

\subsection{UN General Assembly Resolutions}

Multiple resolutions of the General Assembly have addressed internal and cross-border displacement in the context of disasters and climate change, firmly establishing the issue as one of deep concern to the international community, that cuts across sustainable development, disaster risk reduction, and climate change adaptation priorities.

- 'Resolution 75/216 on disaster risk reduction' recognised 'the importance of promoting policies and planning that build resilience and reduce displacement risk in the context of disasters, including through transboundary cooperation. It further called on states, in implementing the Sendai Framework for Disaster Risk Reduction 'where appropriate, to incorporate considerations regarding the risk of disaster displacement, in accordance with national circumstances, making use of practical guidance to support the achievement of target (e), and recalls in this regard the relevant voluntary "Words into action" guidelines.'

- 'Resolution 75/124 on International cooperation on humanitarian assistance in the field of natural disasters, from relief to development' extensively addressed the issue, highlighting the importance of national legal and policy measures to prevent and prepare for displacement, protect people during displacement, and facilitate durable solutions, making specific reference to the 1998 Guiding Principles on Internal Displacement, as well as guidelines issued by the Inter-Agency Standing Committee. The Resolution expressly identified the interconnected priorities of sustainable development, climate change adaptation, and disaster risk reduction, calling upon Member States, the United Nations, and humanitarian and development organisations:

... to integrate the building of resilience and human mobility into relevant strategies, plans and legal frameworks, in particular regarding disaster risk management and climate change adaptation, as integral elements of sustainable development at the national and regional levels so as to help

7 UNGA, Resolution 75/216 on 'Disaster Risk Reduction' (29 December 2020). 
to prevent and mitigate displacement in the context of disasters and the adverse effects of climate change. ${ }^{8}$

Importantly, the Resolution identifies displacement in the context of slower onset processes as well as the more frequently considered suddenonset hazard events. Although not referenced in the Resolution, it reflects many of the important points raised by the UN Special Rapporteur on the human rights of internally-displaced persons in her report on internal displacement in the context of the slow-onset adverse impacts of climate change, which is discussed in more detail below.

A similar call for integrating displacement considerations into disaster risk reduction and through strengthening the humanitarian development nexus was issued in 'Resolution 75/127 on Strengthening of the coordination of emergency humanitarian assistance of the United Nations. ${ }^{9}$

- 'Resolution 75/164 on Assistance to refugees, returnees and displaced persons in Africa' recognised 'the increase in the number and scale of disasters, including those related to the adverse effects of climate change, which in certain circumstances may contribute to displacement and additional pressure on host communities', and called for the strengthening of 'efforts aimed at addressing the needs of persons displaced within the context of such disasters', noting 'the importance of sharing best practices to prevent and prepare for such displacements.' ${ }^{10}$

- 'Resolution 75/163 on the Office of the United Nations High Commissioner for Refugees' expressed 'concern about the challenges associated with climate change and environmental degradation to the operations of the Office of the High Commissioner and the assistance it provides to vulnerable populations of concern across the globe', and urged UNHCR to 'continue to address such challenges in its work ....'11 In addition to its more operational engagements, one of the ways in which the Office has engaged with the issue is through issuing legal guidance on the application of the international law in the context of cross-border disaster- and climate-related displacement. The legal guidance is considered below.

8 UNGA, Resolution 75/124 on 'International cooperation on humanitarian assistance in the field of natural disasters, from relief to development' (21 December 2020).

9 UNGA, Resolution 75/127 on 'Strengthening of the coordination of emergency humanitarian assistance of the United Nations' (21 December 2020).

10 UNGA, Resolution 75/164 on 'Assistance to refugees, returnees and displaced persons in Africa' (23 December 2020).

11 UNGA Resolution 75/163 on the 'Office of the United Nations High Commissioner for Refugees' (23 December 2020). 


\section{'Legal Considerations regarding Claims for International Protection} Made in the Context of the Adverse Effects of Climate Change and Disasters'

The 'Legal Considerations' paper was issued by the UN High Commissioner for Refugees (UNHCR) on 1 October 202O, as part of UNHCR's Strategic Framework for Climate Action. It addresses claims for international protection that may be brought under the 1951 Convention Relating to the Status of Refugees and its 1967 Protocol, as well as the 1969 OAU Convention Governing Specific Aspects of Refugee Problems in Africa and the 1984 Cartagena Declaration on Refugees. Without seeking to expand the international legal definition of a refugee, the paper frames cross-border displacement in the context of disasters and climate change firmly within a social paradigm, that sees harm that arises in the context of hazard events as reflecting pre-existing patterns of exposure and vulnerability, triggering the relevance of international refugee law in certain limited circumstances based on a legally sound interpretation of the criteria in the refugee definition in the 1951 Convention, as well as regional instruments. This approach is in contrast to earlier doctrinal work, including by UNHCR, which tended to ignore this social dimension. ${ }^{12}$

Building on the recognition in the important case of 'AF (Kiribati)' before the New Zealand Immigration and Protection Tribunal, the 'Legal Considerations' recognises that 'No special rules exist for determining refugee claims made in this context.'.3 Consequently, each element of the refugee definition at Article $1 \mathrm{~A}(2)$, which requires the claimant to establish that she is unwilling or unable to return to her home country owing to 'a well-founded fear of being persecuted for reasons of race, religion, nationality, membership of a particular social group or political opinion' is considered in turn. The doctrinal points raised in the document reflect insights developed elsewhere in jurisprudence, academic writing, and UNHCR's own legal guidance, and highlight some of the kinds of circumstances that may give rise to recognition of refugee status. Importantly, the 'Legal Considerations' paper recognises that refugee status may arise not only in situations relating to the direct and intentional infliction of serious harm, but also where pre-existing patterns of discrimination exacerbate exposure and vulnerability, including in situations that are not limited to sudden-onset hazard events. The possibility of disasters and climate change interacting in various ways with armed conflict is recognised,

\footnotetext{
12 For a discussion of the social paradigm in contrast to the hazard paradigm, consider Matthew Scott, Climate Change, Disasters and the Refugee Convention (Cambridge University Press 2020).

13 Para. 6.
} 
as is the fact that, despite internal relocation often being available, a careful individual assessment will be required, including consideration of the environmental conditions prevailing in any part of the country where relocation may be considered.

Specific considerations relating to the OAU Convention and the Cartagena Declaration focus primarily on the distinctive 'events seriously disrupting public order' clause, which is found in these documents but not the original $195^{1}$ Convention. Calling for an evolutionary approach to interpretation, UNHCR asserts that certain 'people displaced by the adverse effects of climate change and disasters can be refugees under regional refugee criteria', and cites Ethiopia as one country that has expressly adopted this position. ${ }^{14}$ Brief recognition of the possibility of individuals securing complementary protection is made, with reference to the 'Teitiota' decision in the Human Rights Committee, ${ }^{15}$ and the availability of the broader category of temporary protection and stay arrangements is also noted.

The key contribution made by UNHCR in this document is its consolidation of jurisprudence, academic literature and other material that, together, establishes that international protection for persons displaced across borders in the context of disasters and climate change is somewhat more widely available than is often recognised. Together with the 'Teitiota' decision from 2019, these 'Legal Considerations' provide a pathway for some individuals to secure recognition of refugee status or eligibility for complementary protection.

\subsection{Report of the UN Special Rapporteur on the Human Rights of Internally Displaced Persons on Displacement in the Context of the Slower Onset Adverse Impacts of Climate Change}

Although the number of people who cross international borders in the context of disasters and climate change is not known, internal displacement is increasingly well-documented. In 2020, more than 30 million people were internally displaced, predominantly in the context of more sudden-onset hazard events like floods, cyclones, and earthquakes. ${ }^{16}$ Although the Internal Displacement Monitoring Centre (IDMC) is innovating ways of calculating the number of people displaced in the context of slower-onset disasters and sea-level rise, there remains no international dataset for this group of people, not least

\footnotetext{
14 Legal Considerations (n 4) para 14.

15 Discussed in Matthew Scott, 'Migration/Refugee Law (2019)' (2020) 2 Yearbook of International Disaster Law, 519-528.

16 Internal Displacement Monitoring Centre, Global Report on Internal Displacement (2021), available at <https://www.internal-displacement.org/global-report/grid2021/>.
} 
because of the complexity of separating environmental pressures from economic, social, political and other factors.

Cecilia Jimenez-Damary, the UN Special Rapporteur on the human rights of internally displaced persons, presented a report on 21 July 2020 to the UN General Assembly on internal displacement in the context of the slower onset adverse impacts of climate change. ${ }^{17}$ The report builds on consultations with states and international actors. She connects the report to ongoing initiatives to recognise the right to a safe, clean, healthy and sustainable environment, as well as processes within the UN Framework Convention on Climate Change, and other elements of the post-2015 international frameworks, including the Sustainable Development Goals, the New Urban Agenda, the Sendai Framework for Disaster Risk Reduction 2015-2030, the Agenda for the Protection of Cross-Border Displaced Persons in the Context of Disasters and Climate Change, and the Global Compact on Safe, Regular and Orderly Migration. The report also highlights the 2009 African Union's Kampala Convention for the Protection and Assistance of Internally Displaced Persons in Africa, the Framework for Resilient Development in the Pacific, and other regional as well as national legal and policy frameworks, as being relevant to the topic. Clearly, internal displacement in the context of disasters and climate change has emerged as an issue of global concern, as reflected in this report and the multiple legal and policy documents that expressly address it.

Although a large part of the report is focused on describing the phenomenon, including how it relates to the CoviD-19 pandemic, it also contributes a clear international legal perspective on the issue, adopting a human rightsbased approach, grounded in the 1998 'UN Guiding Principles on Internal Displacement'. The approach highlights substantive as well as procedural rights that states must respect, protect, and fulfil in the course of preventing and preparing for displacement, protecting people during evacuation and throughout displacement, and facilitating durable solutions. It devotes considerable attention to the non-discrimination and equality obligation, engaging with the particular situation of indigenous people, children, older people, persons whose livelihoods depend on natural resources, and many others, including recognition of the gender dimension. Reflecting the call under the post-2015 international frameworks for a multi-level, multi-stakeholder approach, the report also emphasizes the importance of local government and participation of civil society, the private sector, and faith-based organisations. Concluding recommendations highlight that the issue of internal displacement remains

17 UN Special Rapporteur on the human rights of internally displaced persons, Report $\mathrm{A} / 75 / 207$ (2020), available at $<$ https://undocs.org/A/75/207>. 
very much a matter that needs to be addressed within the domestic legal order, with international law providing a framework that can help to shape law, policy, and practice.

From the foregoing, it is clear that the international legal and policy framework reflects an increasingly sophisticated appreciation of the phenomenon of displacement in the context of disasters and climate change. More concrete measures to address the phenomenon are found at the regional level.

\section{$3 \quad$ Asia and the Pacific}

In 2020, the UN Economic and Social Council for Asia and the Pacific (UNESCAP) held a series of consultations on the implementation of the Global Compact on Safe, Regular and Orderly Migration. Emerging from the wideranging discussions were several recommendations relating to displacement in the context of disasters and climate change, including the following:

- There is a need for more research, including on the effects of climate change and disasters on migration, as well as on the intersectionality of vulnerabilities;

- A lack of legal provisions relating to people who migrated because of climate change contributed to a lack of protection;

- Potential migration due to climate change was not adequately reflected in long-term planning. ${ }^{18}$

Insights from the consultations will inform deliberations at the 'Asia-Pacific Regional Review of Implementation of the Global Compact on Safe, Regular, and Orderly Migration' in 2021.

In the Pacific, work continued within the framework of the ongoing IOM-led Pacific Climate Change and Human Security Programme that brings together the Pacific Islands Forum Secretariat and UN and other actors including UNEsCAP, ILO, OHCHR and the Platform on Disaster Displacement. ${ }^{19} \mathrm{~A}$ series of six virtual regional policy consultations were convened during the year. ${ }^{20}$

18 UNESCAP, Implementing the Global Compact for Safe, Regular and Orderly Migration: a synthesis of the outcomes of stakeholder consultations (ESCAP/GCM/2O21/CRP.2), available at <https://www.unescap.org/sites/default/d8files/event-documents/ESCAP_GCM _2O21_CPR2_ENG.pdf $>$.

19 For more information on the programme, please see: <https://environmentalmigration .iom.int/projects/pccmhs>.

20 For a summary of the policy consultations, please see: <https://environmentalmigra tion.iom.int/sites/default/files/PCCMHS\%2oQuarterly\%2oupdate\%2oIssue\%2O2\%2O 
A process leading to the tabling of a motion for a resolution 'on the impact of climate change on vulnerable populations in developing countries' was commenced in the European Parliament. A draft report was produced by the Committee on Development, ${ }^{21}$ which called 'for a common and coordinated international response led by the EU aimed at making progress in the implementation of recognition, protection and support measures for people who are compelled to move within and between countries in the context of disasters and the adverse effects of climate change'. Significantly, and in recognition that the European Union itself is not immune to the adverse impacts of disasters, the draft report invoked the 1998 Guiding Principles on Internal Displacement and the Kampala Convention in calling for the EU 'to analyse and adopt new approaches ... into the domestic laws of EU Member States and of third states through bilateral and regional agreements.22 This initiative comes on the heels of a similar Resolution of the Parliamentary Assembly of the Council of Europe on a 'Legal Status for 'Climate Refugees', described in the 2019 edition of this Yearbook, indicating a growing momentum within EU and Council of Europe Member States towards some form of legal framework to address displacement in the context of disasters and climate change. The motion for a resolution is scheduled for its first plenary reading the European Parliament on 24 March 2021. ${ }^{23}$ A detailed review of existing practice at the EU level as well as at the level of Member States was commissioned by the Parliament's Committee on Civil Liberties, Justice and Home Affairs (LIBE Committee), and provides important insights that can further contribute to the development of the law at the EU regional level. ${ }^{24}$

Less open to the prospect of receiving people displaced across borders in the context of disasters and climate change was the European Pact on

March\%202021.pdf> and <https://environmentalmigration.iom.int/sites/default/files/ PCCMHS\%2oNewsletter\%2oNovember\%2O2O2O_o.pdf>.

21 European Parliament, Committee on Development, 'Draft Report on the Impacts of Climate Change on Vulnerable Populations in Developing Countries' (2020/2042(INI)) 11 September 2020 .

22 Interestingly, this call echoes a much earlier 2009 call by the Parliamentary Assembly of the Council of Europe. See Parliamentary Assembly of the Council of Europe, 'Environmentally Induced Migration and Displacement: A 21st-Century Challenge' (Recommendation 1862 (2009)) 30 January 2009.

23 See <https://oeil.secure.europarl.europa.eu/oeil/popups/ficheprocedure.do?lang=en\&re ference $=2020 / 2042(\mathrm{INI})>$.

24 See <https://www.europarl.europa.eu/RegData/etudes/STUD/2020/655591/IPOL_STU (2020)655591_EN.pdf>. 
Migration and Asylum, which 'offers a fresh start' to the task of 'build[ing] a system that manages and normalises migration for the long term and which is fully grounded in European values and international law'. The pact, which the European Council on Refugees and Exiles considered 'risks exacerbating the focus on externalisation, deterrence, containment and return, ${ }^{25}$ recognises climate change as a driver of migration, but frames the role of the EU solely in terms of development cooperation, climate change adaptation, and disaster risk reduction, as a way of 'building economic opportunity and addressing root causes of irregular migration' in order to 'help people feel that their future lies at home.'.26

Africa

On 26 February, the Intergovernmental Authority on Development (IGAD) adopted the 'Protocol on Free Movement of Persons in the IGAD Region across the Horn of Africa, Nile Valley and the African Great Lakes. ${ }^{27}$ Focused predominantly on general provisions relating to freedom of movement and residence, the Protocol also contains a specific provision at Article 16 relating to movement of persons affected by disasters. Significantly the provision provides for anticipatory movement, as well as movement during or in the aftermath of disaster. Further, Member States 'shall take measures to facilitate the extension of stay or the exercise of other rights' for affected people 'when return to their state of origin is not possible or reasonable'.

Member States of the Southern African Development Community (SADC) began considering displacement in the context of disasters and climate change within the Thematic Working Group on Climate Change and Disaster Risk Reduction. As part of this work, IOM has, in consultation with the Regional Interagency Standing Committee (RIASCO), and with contributions from UN agencies and INGOs and inputs from SADC Member States, developed a draft Regional Framework for Action to Address Disaster Displacement in Southern

25 ECRE, 'Joint Statement: The Pact on Migration and Asylum: to provide a fresh start and avoid past mistakes, risky elements need to be addressed and positive aspects need to be expanded', 6 October 2020, available at <https://www.ecre.org/the-pact -on-migration-and-asylum-to-provide-a-fresh-start-and-avoid-past-mistakes-risky -elements-need-to-be-addressed-and-positive-aspects-need-to-be-expanded/>.

26 Ibid., 19-20.

27 Available at $<$ https://environmentalmigration.iom.int/sites/environmentalmigration/

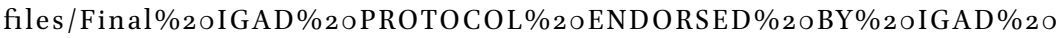
Ambassadors\%2oand\%2oMinisters\%2oof\%2oInterior\%2oand\%2oLabour\%2o Khartoum\%2026\%2oFeb\%2O2O2O.pdf>. 
Africa. ${ }^{28}$ The mission statement, as currently formulated in the draft, reads: 'Building a comprehensive approach to better addressing disaster displacement in southern Africa, by strengthening the prevention of, responses to and durable solutions for disaster displaced persons, as well as mainstreaming their human rights, through partnership and joint interventions'.

At the regional level, the South American Conference on Migration (SACM) currently chaired by Argentina (202O-2021) has proposed to create a new working group devoted to addressing and analysing the human mobility-environment nexus in South America. If approved by SACM member countries, this working group will aim to follow up the work and different initiatives by the SACM in this area, including the adoption of the SACM regional guidelines to protect persons displaced across borders due to disasters and climate change in 2018.

Renewed climate ambition in Latin America and the Caribbean has also entailed stronger attention to human mobility in climate change commitments. For instance, the new Nationally Determined Contribution from Mexico calls to 'identify and address forced displacement of people due to the negative impacts of climate change'. Grenada similarly recalls the ambition to involve the diaspora in development and the commitment to strengthen 'resilience to respond to impacts beyond the limits of adaptation and addressing human mobility and settlements'.

In Peru, the Ministry of Environment has advanced the development of a Plan of Action to prevent and address forced migration due to climate change, as per the 2018 Climate Change Law Act and its 2019 implementation decree, described in the 2020 edition of this Yearbook. ${ }^{29}$

28 Email communication with IOM on file with the author.

29 Thanks to Pablo Escribano (IOM) and Juan Carlos Méndez (PDD) for contributions to this section. 